etc. ; neither prin nor swelling ; tubercle bscilli found in urine. On cystoscopic examination: Dark red swollen mucous membxane round orifice of left ureter; urine from right, specific gravity 1020, normal ; left, 1005, containing pus. Treatment: Nephrectomy, and injections of taberculin. Result so far as known to date: Doing well (three months after operation).

CASE XXII.-Female, aged 28. Family history of tabercle present; left side. Early symptoms : Frequency of micturition etc.; neither pain nor swelling; tubercle bacilli found in urine On cystoscopic examination : Left ureteral orifice surrounded by swollen, woolly-looking mucous membrane; patches of redness on left side of bladder; urine from right, speciflc gravity 1020, normsl ; left, specific gravity 1005 , containing pus. Treat. ment: Nephrectomy by Dr. John Campbell. Result so far as known to date: Doing well (two months after operation).

CASE XXIIr.-Female, aged 31. Family history of tubercle absent; both kidneys affected. Early symptoms: Left-sided renal colic, and frequency of micturition; both kidneys enlarged; no tubercle bacilli found in urine. On cystoscopic examination: A large irregular ulcer at base of bladder; left ureteral orifice buried in this; right orifice just at edge of vlcer; under $\mathrm{CHCl}_{3}$ with catheters in ureters, no urine; even after injection of indigo-carmine none could be seen flowing into bladder. Result so far as known to date: In statu quo; had anuria for twenty-four hours after examination.

CASE XXIV.-Male, aged 23. Family history of tubercle present ; right side; Early symptoms: Right-sided renal colic; righ kichney enlarged ; tubercle bacilli was found in urine. On cystoscopic examination: Right ureteral orifice round, red and dilated; red patches in neighbourhood ; right ureter not catheterized; left, specific gravity under 1005, containing albumen. Treatment : Medical. Result so far as known to date: Going preatment: Medical.

\section{SUPRAPUBIC DRAINAGE OF THE BLADDER} AS AN ALTERNATIVE TO PROSTATECTOMY AND AS A RELIEF OPERATION.

By J. B. PIKE, M.R C.S.ENG. HONORARY SURGEON, LOUGHBOROUGH HOSPITAL.

Prostatrctomy in selected cases, performed by an operator who has ample experience, is doubtless a satisfactory measure. If a large margin of risk had not to be allowed for no surgeon would condemn a patient to the inconveniences of catheter life. Suprapubic drainage is a middle course, and in many things a middle course, avoiding Scylla and Charybdis, is advisable. In cases of cancer of the bladder radical removal is a thing to be eimed at, but how often does it succeed? The bladder is removed and the ureters are transplanted, either fin the abdominal wall or the rectum. In both methods the result is very doubtful, even though at first a good result may appear to have been gained. There are, however, some cases in which removal, either of the growth or the organ, seems hopeless; and here as a relief measure suprapubic drainage appears to have a valuable place. The two following cases illustrate these remarks :

\section{CASE I.}

J. M., a farmer, of good physique, aged 69 years, was admitted to the Loughborough Hospital on October 25th, 1904 . prostate and partiy to a very tight traumatic stricture of the membranous portion of the urethra. Catheterism was unsuccessful, and aspiration gave temporary relief. On the following day a puncture was made above the pubes with a trocar, and a Jacques catheter inserted through the cannula. The patient managed somehow to get this out in the night, and thus rendered cystotomy imperative under somewhat nnfavourthus rendered cystotomy imperative under somewhat anfavour-
able conditions. The bladder was stitched to the edges of the able conditions. The bladder was

wound and a large tube inserted. in consultation with Mr. Bond of Leicester, and the operation was not pressed. The patient decided against it. In about six weeks he returned to his home and drained the bladder with some sort of rubber tube for about two years.

Having allowed the sinus to close he came to the hospital with retention in March, 1907. Relief was given by aspiration, and he passed water by the natural channel with increasing difficulty until November, 1907, when he sent for me to visit him. The only thing to do was to reopen the bladder, and this was done through the scar tissue, partly by incision, partly by trocar, the cannula being retained. We made various experiments with silver tubes, and at last got one to our liking. Since that time there has been very little trouble with the water, and the general condition has for the most part been good, his life having been quite activ

\section{CASE II.}

This was a case of multiple papilloma above the trigone. An exploratory cystotomy was done by Mr. Bond. Owing to the multiple nature and situation of the growth, it was decided that nothing further could be done. As I felt persuaded that the frequent micturition would become very painful if the wound closed, I kept a rubber tube permanently in the bladder. The cystotomy was done in March, 1909, and for many months great relief was obtained.

In these very painful cases the alternative is a poor thing at best, but slight relief is something to the good, and it may be desirable that life should be prolonged. I think these cases may be taken in evidence of the value of suprapubic drainage of the bladder.

\section{THE INCIDENCE OF TUBERCULOSIS IN CHILDHOOD.*}

By Priv. Doz. Dr. FRANZ hambURger, VIENA.

Is conjunction with $R$. Monti, I have endeavoured, by extensive investigation, to determine the incidence of taberculosis among the children of Vienna. We adopted the method of examining only children who were suffering from acute infectious diseases (scarlatina and diphtheria). In this way we obtained material which represented fairly accurately the real state of child-life in Vienna. All the children were first tested by Pirquet's cutaneous reaction. Those reacting negatively were, after two days, subjected to a subcutaneous tuberculin injection of $1 \mathrm{mg}$. Those of the children who showed a distinct inflammatory reaction at the injection point of at least three days' duration, were looked upon as tuberculous, as well as those showing a positive reaction.

In this way Monti and I found that out of 532 patients suffering from diphtheria or scarlatina 271 reacted positively-that is, about 50 per cent.

\begin{tabular}{|c|c|c|c|c|c|c|c|}
\hline \multirow{3}{*}{$\begin{array}{c}\text { Out of } \\
, "\end{array}$} & \multicolumn{3}{|c|}{23 children in the } & \multicolumn{2}{|c|}{ lst year } & \multicolumn{2}{|c|}{0 reacted- } \\
\hline & 45 & ", & ", & 2nd & ", & 4 & ", \\
\hline & 56 & $"$ & ", & $3 \mathrm{rd}$ & ," & 11 & $"$ \\
\hline " & 75 & $"$ & $"$, & 4th & ", & 24 & " \\
\hline " & 50 & ", & $"$ & Sun & $"$ & 30 & $"$ \\
\hline , & 63 & $"$ & ", & 6th & $"$ & 3. & $"$ \\
\hline ", & 46 & ", & $"$ & 7 & ", & 22 & $"$ \\
\hline$"$ & 35 & $"$ & 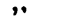 & ot & $"$ & 24 & $"$ \\
\hline$"$ & 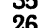 & $"$ & $"$ & 10th & $"$ & 22 & $"$ \\
\hline$"$ & 29 & $"$ & $"$ & 11th & $"$ & 27 & $"$ \\
\hline ,", & 19 & $"$ & ", & 12th & ," & 18 & $"$ \\
\hline ," & 17 & ," & ," & 13th & ," & 16 & ", \\
\hline , & & ," & ," & & & 16 & \\
\hline
\end{tabular}

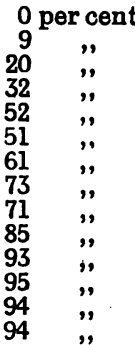

These results show how the frequency of tuberculosis in childhood increases from year to year. $t$ When child. hood is divided into six periods, the following percentages with regard to the frequency of the disease are obtained:
1. First year
2. Second year
3. Third to fourth year
4. Fifth to sixth year
5. Seventh to tenth year ...
6. Eleventh to fourteenth year

$\ldots .2$ per cent. +
$\ldots .9$
$\ldots .27$

It follows that nearly all persons in Vienna of over 14 years of age are already "tuberculous." This fact appears extraordinary and almost incredible. It is only appreciated when we investigate the fact further, and con sider that tuberculosis in childhood is a relatively harmless disease. It runs its course commonly without giving rise to any symptom. This explains the fact why so many children give a positive tuberculin reaction without at the same timo developing any stronger symptoms of disease. It may even be said that the majority of children who are only affected by tuberculosis after the fifth or sixth year show no signs, or at least very fow signs, of disease. That is the result of the constant increase of the frequency of tuberculosis on the one hand and the decrease of the tuberculous morbidity with increasing age on the other. This is further demonstrated by Pollak's clinical observations.

It must be fully understood that tuberculous infection and tuberculous morbidity are two conceptions which it is difficult to separate. While in the first, and also in the second, year the majority of children infected with tuber.

* Read at the Tuberculosis Conference, Edinburgh, July, 1910 t The percentage for the first year is not reliable, because the number of children examined (23) is too smoll. The real incidence of Cerculosis in this age, according to Sperk, is about 2 per cent.

t Corrected figure, according to sperk. 
culosis give also clinical manifestations of disease, older children overcome the primary taberculous infection, the more probably the older they are at the time of the infection, without showing more pronounced symptoms of disease.

The prognosis of tuberculosis developed in the several years becomes better from year to year. According to an approximate calculation, the mortality from fresh tubersulosis in the several periods is as follows:
1. First year $\quad \ldots \quad \ldots \quad \ldots 70$ per cent.

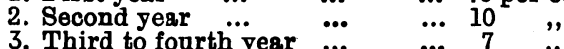

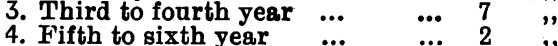

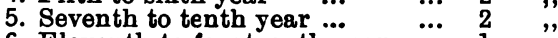
6. Eleventh to fourteenth year ... 1 ,"

It is, therefore, clear that tuberculous morbidity decreases from year to year, although the incidence of tuberculous infection increases from year to year.

The statistics regarding the incidence of tuberculosis among the children of Vienna obtained by means of tuberculin reaction are confirmed by post.mortem results in recent years. Since the autopsy of children of over 6 years has been made with special attention to the probable existence of a tuberculous focus, an almost equally great frequency of tuberculosis in Vienna has been determined by autopsy as by the tuberculin test on the living patient. If in former years the statistics obtained by autopsy as to the incidence were much lower, this is explained by the fact that the examination was not sufficiently searching.

It must be specially emphasized that the figures obtained by Monti and myself refer only to the poorer population of Vienna. Probably in the wealthier popula. tion a much lower percentage of positive tubercalin reac tion would be obtained than is the case in the poorer classes. In the case of the well-to.do open pulmonary taberculosis-the only source of tubercalosis in childhood -is not only much more rare than in the case of the poor, but the wealthy protect themselves mach more carefully from every infection.

The question now is whether the figures obtained by Monti and myself in Vienna are applicable to other towns as well. I think they are. If Ganghofer obtained lower figares in Prague than Monti and myself in Vienna, this is explained by the fact that the cutaneous reaction does not reveal all taberculosis. The "Stich" reaction-that is, the local subcataneous reaction-must also be employed if every case of taberculosis is to be detected. That the frequency of tuberculosis is approximately as great in other large towns as in Vienna is supported by a recent publication by Nothmann, who gives almost the same tigures for Düsseldorf as .Monti and myself for Vienna. One may assume the same figures with regard to the incidence of taberculosis in childhood in all the larger towns as I now present with regard to Vienna. In the country the incidence is probably rather less, and above all more irregular, than in the town.

Since the majority of persons develop tuberculosis in childhood we cannot be surprised that tabercalous sym. ptoms are so common in childhood. Indeed, taberculosis in children usually offers very different symptoms to those of adults.

Conclusions.

1. The majority of persons become infected by tuberculosis in childhood.

2. The frequency of tuberculous infection increases from year to year, whilst tuberculous morbidity-that is, the frequency of manifest tuberculous disease-decreases from year to year.

3. Tuberculosis is very commonly latent, producing no symptoms; this is especially so if the infection dates from the third or fourth year.

4. The prognosis of taberculosis in childhood becomes more favourable the older the person is at the time of the first infection.

THE extra.parliamentary commission which is drawing up administrative regulations under the French old age pensions law will not report before November, so that the law cannot come into force until this time next year. It is estimated, however, that $£ 1,800,000$ will be required in 1911-that is to say, about one-third of the total estimated expenditure for a year.

\section{ADDRESS ON}

\section{THE PREVENTION OF MORTALITY FROM} PELVIC OPERATIONS.*

By H. MACNAUGHTON.JONES, M.D., M.CH., M A.O., PRESIDENT OF TEE OBSTETRICAL AND GYNAECOLOGICAL SECTION OF THE ROYAL SOCIETY OF MEDICINE.

\section{[ABstract.]}

[Dr. Macnadghton-Jones discussed the increased responsibility attached to operative interference through the perfection of modern preventive methods in diagnosis, preoperative measures, technique, and the post-operative management of the patient, entering separately into several points in each. The pernicious effects of delay in diagnosis were emphasized, as also the incalcalable harm done by the present-day resort to boomed remedies, involving the postponement of seeking professional advice, and the danger arising from the reliance on the part of the public on popular medical literature which takes the form of some indispensable Household Medical Cookery Book, compiled on the "Every Man His Own Lawyer" principle. The exceptions in which a difficulty was found in making an early diagnosis were summarized. The pleading was not so much for a definite differentiation of the nature of conditions, as an early recognition of an abnormality, which, in the great proportion of cases, either at the time requires, or in the near futare will demand, surgical interference. Vain temporizing, or the lulling of a patient into a sense of false security added in various ways to the magnitude, complications, and consequent risks of the future operation.]

How (he asked) is not life lost and operative risk increased by dallying with appendical disease, ectopic gestation, taberculous and gonorrhoeal salpingitis, ovarian blood cysts, adnexal carcinoma, streptococcus and $B$. coli abscess of the tube or ovary, early carcinoma of the portio, exhausting haemorrhages, fibromitis, degenerations, adhesions, and the renal and cardiac complications of myoma of the uterus? The delusions that the ovaries are not frequently invaded by malignant disease; that myomata are not often the sources of fatal degenerations, or that the menopause is a time when expectancy is justified, and which explains various pathological conditions, of which the patient will be relieved when the climacteric has ceased, are myths of the past. Now we know that jast in proportion to the years after 50 the risks and fatality from myomata are increased by necrosis and malignant degenerations.

The immediate antecedents of an operation might well be divided into the surroundings, and the preparation of the patient. Either we are ourselves the dupes of a fanciful, faddish system, and a Will.o'-the-wisp hunt after an impossible ideal, or we are striving to secure on scientific and assured grounds the greatest immunity from risk of those who place their lives in our hands. If we are justifed in the steps we insist on as essential to effect the latter in our pablic hospitals and their costly theatres, with the refinements of aseptic precautions in tiled walls, mosaiced floore, with special drainage, filtered air, tem. perature regulators, sterilizers, pedalled sinks and dressing holders, airtight cases and glass operating tables-ought we not to come as near them as possible in our cottage hospitals and nursing homes?

There are cases in which, short of letting the patient die from her ignorance, we should absolutely refuse to operate, or before consenting, by the plainest speaking place the responsibility on her and her friends. It is not for as to condone a line of conduct which we believe increases enormously the risk to life.

There might be in every large town self-supporting sanatoriums, so farnished and equipped as to meet the requirements of the better.off classes, or the more modest or unpretentious demands of the poorer, and the charges should be regulated accordingly. The control might be municipal, but this need not exclude the right of private enterprise in the erection and conduct of the institation. Each sanatorium would have at least two operating theatres, and the necessary preparation, anaesthetizing, photographic, and radiogr $\rightarrow$ phic rooms, with one general

* Delivered to the Maidstone Division of the South-Eastern Branch of the British Medical Association, June 23rd, 1910. 